\title{
Determinants and prevalence of childhood overweight and obesity in pre-school children of Duwakot, Bhaktapur
}

\author{
Sushil Kharel', Binod Raut ${ }^{2}$
}

\section{Author(s) info:}

${ }^{1}$ Department of Physiology,

Kathmandu Medical College and

Teaching Hospital, Kathmandu,

Nepal

${ }^{3}$ Department of Pharmacology,

Kathmandu Medical College and

Teaching Hospital, Kathmandu,

Nepal

\section{Correspondence:}

Dr. Sushil Kharel, BDS, $M D$

Department of Physiology,

Kathmandu Medical College and

Teaching Hospital, Kathmandu,

Nepal

Email:

drsushilkharel@gmail.com

\begin{abstract}
Introduction: Adverse dietary patterns and sedentary lifestyle predispose to overweight-related non-communicable diseases both in children and in adults. In Nepal, childhood overweight is one rapidly growing public health concern in the urban areas. Many studies have focused on the relationship between overweight and its associated risk factors. We aimed to find the prevalence of overweight including obesity and its determinants in pre-school children aged 2 to 4 years in Duwakot community, Bhaktapur..
\end{abstract}

Materials and methods: In a community-based cross-sectional survey, total 122 pre-school children both males and females of age between 2-4 years were studied. A structured questionnaire was used to obtain information on socioeconomic characteristics and life style factors of children. WHO Anthro Software Version 3.2.2 was used for analyzing anthropometric parameters of the children.

Results: The prevalence of overweight in pre-school children was $13.9 \%$. The prevalence of overweight including obesity was significantly higher among male children (17.7\%) than female children (10\%). The study revealed that overweight was significantly associated with sedentary lifestyles of children and higher socioeconomic status of the family.

Conclusions: The magnitude of overweight is big and increasing rapidly in Nepal due to sedentary lifestyles and improper dietary habits among pre-school children, especially in the cities. Proper interventions should be implemented to minimize the overweight among pre-school children in order to avoid further health ailments in future.

Keywords: Duwakot community, obesity, pre-school children 


\section{INTRODUCTION}

Modern unhealthy dietary practices and increasing sedentary lifestyle patterns predispose to overweight-related non-communicable diseases both in children and in adults.[1] The worldwide prevalence of overweight and obesity in children and adolescents has increased exponentially in recent years.[2] The mechanisms involved in weight gain and the development of obesity in children are multi-factorial and include hereditary, environmental, and physiological factors. The vitality and importance of each these processes varies significantly between individuals and populations and is a new interest of ongoing research.[3] Increasing trends in obesity levels have been found even in very young preschool children and are predicted to continue and increase. Based on an analysis of 450 nationally representative surveys from 144 countries, the World Health Organization (WHO) estimated that the prevalence of children below age 5 years old with a BMI $>+2 \mathrm{SD}$ (equivalent to the 98th percentile) increased from $4.2 \%$ in 1990 to $6.7 \%$ in 2010 , and is expected to reach $9.1 \%$ in 2020.[4] The overall prevalence of overweight, including obesity, in school children in European countries was predicted at 20.5\%: $15.6 \%$ for overweight and $4.9 \%$ for obesity. The proportion of overweight and obesity was $24.5 \%$ in Eastern Asia countries and $11.9 \%$ in the Western Asia regions. [5] There are two important reasons to target childhood overweight. First, overweight and obese children are much more likely to become obese when they become adults as compared to normal BMI children, and second, it is more challenging for these obese adults to lose the excess weight once they become obese. Newer drugs and therapies for managing obesityrelated health problems have been developed but these procedures are costly and have their own complications. Thus, prevention of childhood obesity with more focus on increased physical activity is of utmost importance.[6,7] Physical activity is the key component for prevention and management of overweight. Preschool children require unstructured activities and thus will benefit from outdoor play and games. On the other hand, school going children and adolescents require at least 60 minutes of daily physical activity out of which 30 minutes should be structured activities like sports and supervised exercises.[8,9]

Hence this study was conducted to evaluate the determinants and associated factors commonly related with childhood overweight and obesity as well as to find the prevalence of childhood overweight and obesity. Knowing the extent of the problem and identifying the risk factors related with nutritional status of children in the study area will enable to guide public health policy makers in designing appropriate and effective nutritional intervention programs to address the emerging and serious problem.

\section{MATERIALS AND METHODS}

A community-based cross-sectional study was conducted in pre-school children of Duwakot, Bhaktapur. The study was carried out from December 2018 to March 2019. Simple random sampling method was used. Informed written consent was taken from the parents/guardian and school authority. Self-designed structured questionnaire regarding lifestyle factors of child, economic status of family, etc was given to them. Anthropometric assessment was done. Their weight and height were measured three consecutive times and the mean was taken as their actual weight and height. Anthropometric measurement was done by LG digital weighing machine (with a graduation of 10 grams), stadiometer and non stretchable measuring tape. The condition of weighing machine was checked then was kept on firm flooring; heavy clothing and shoes were removed. Children were told to stand with both feet in the center of the scale and weight was recorded. Height measurement was done by Stadiometer, children were asked to stand up straight with feet and heels together keeping the heels back against the upright section of the stadiometer (arms relaxed by sides). Children were asked to look straight ahead at the marker. Standard indices of physical growth given by WHO weightfor-height that described the overweight status (Weight-for-Height $>+2$ Standard Deviations) of children was considered in this study.

\section{WHO Classification:[10]}

Overweight: Weight for Height $>+2$ Standard Deviations (SD) of the WHO growth standard Median

Obesity: Weight for Height $>+3$ Standard Deviations (SD) of the WHO growth standard Median

Inclusion and exclusion criteria: The pre-school children aged between 2 to 4 years were included. 
Children with difficult cooperation and ill health were excluded.

Statistical analysis was done by universally accepted WHO Anthro Software Version 3.2.2 and SPSS Version 21. $Z$ test was used to calculate the $P$ value. P-value of $<0.05$ was considered as statistically significant.

\section{RESULTS}

A total of 122 pre-school children aged between 2-4 years were enrolled in the study. Of these 122 participants $62(50.8 \%)$ were males and $60(49.2 \%)$ were females. Prevalence of overall overweight (including obesity) was $13.9 \%$. Males were more overweight as compared to females. The prevalence of overweight in male and female population compared to its own counterpart was $17.7 \%$ and $10 \%$ respectively (Table 1 ). Regarding prevalence of obesity, 3 out of the 62 males (4.8\%) and 1 out of the 60 females (1.7\%) had weight-for-height of $>+3 \mathrm{SD}$ of the WHO median value. This gave a total of 4 cases of obesity (overall prevalence of $3.3 \%$ ). The prevalence of obesity in male pre-school children was high $4.8 \%$ as compared to $1.7 \%$ in female children. The right shift of the histogram clearly shows the increasing overweight trend in the country like ours (Fig 1).

Some sociodemographic and lifestyle factors were
Table 1: Weight-for-height prevalence of overweight (including obesity) in the study population (CI 95\%)

\begin{tabular}{|c|c|c|c|}
\hline Groups & $\begin{array}{c}\text { Number (\%) } \\
\text { of overweight } \\
\text { children (>+2SD) }\end{array}$ & $\begin{array}{c}\text { Mean } \\
\mathbf{Z} \\
\text { score }\end{array}$ & $\begin{array}{c}\mathbf{P} \\
\text { value }\end{array}$ \\
\hline $\begin{array}{c}\text { Males } \\
(\mathrm{n}=62)\end{array}$ & $11(17.7 \%)$ & 0.55 & 0.29 \\
\hline $\begin{array}{c}\text { Females } \\
(\mathrm{n}=60)\end{array}$ & $6(10 \%)$ & 0.40 & 0.34 \\
\hline $\begin{array}{c}\text { Total } \\
(\mathrm{N}=122)\end{array}$ & $17(13.9 \%)$ & 0.48 & 0.31 \\
\hline
\end{tabular}

explored (Table 2). Almost all mothers were literate and most households had annual income more than $\$ 2000$. About a quarter of the children had overeating tendency. There were not remarkable differences in junk food preferences, sleep habits, watching TV and preference to indoor/outdoor activities.

\section{DISCUSSION}

In developing countries like Nepal, overweight and obesity in pre-schoolchildren has become a public health concern in the recent times due to its bad

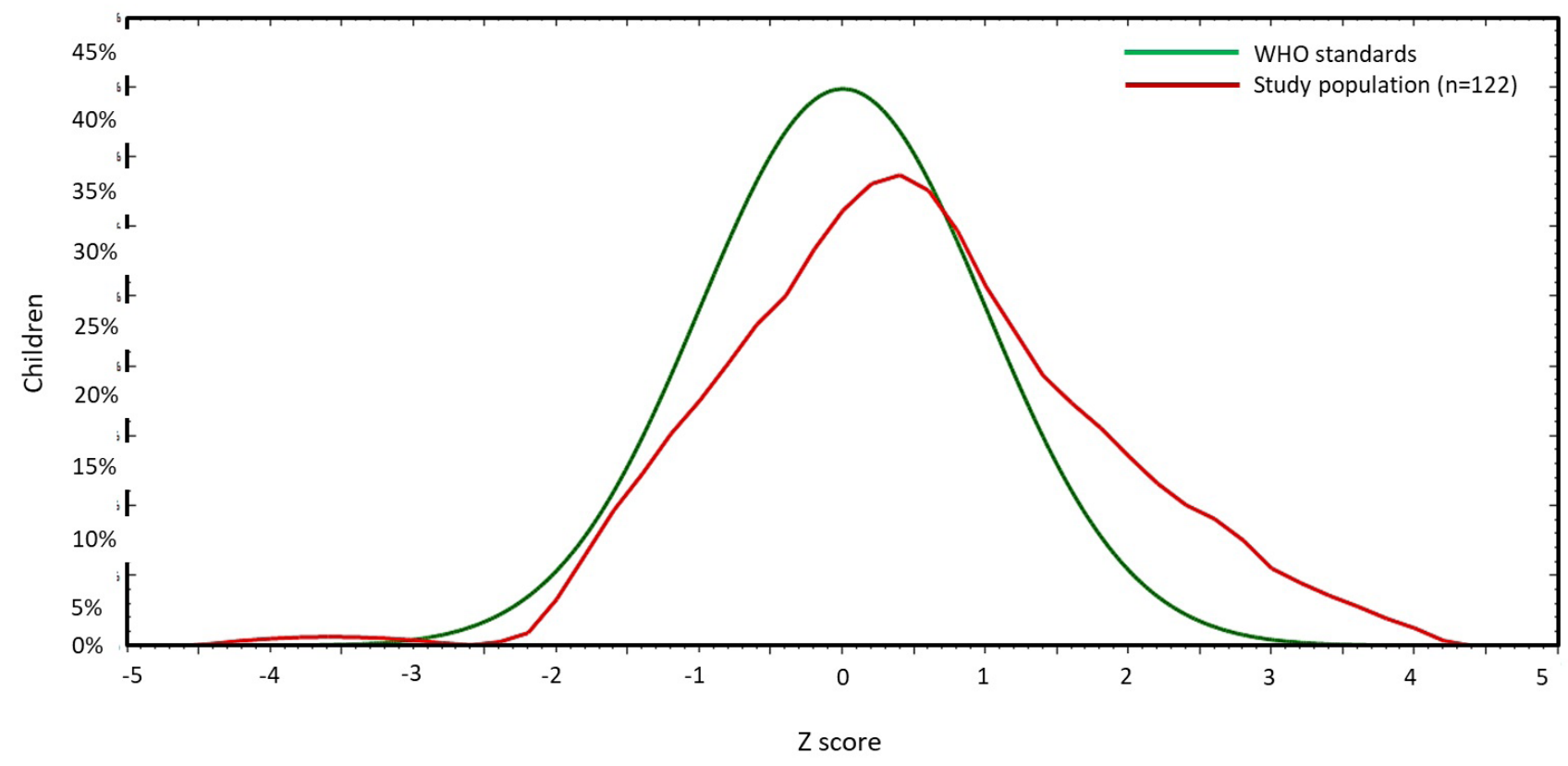

Figure 1: Distribution of pre-school children (weight-for-height) with respect to WHO standards 
Table 2: Sociodemographic and life style characteristics of study population

\begin{tabular}{|c|c|c|c|}
\hline \multicolumn{2}{|r|}{ Variables } & Number & Percentage \\
\hline \multirow{2}{*}{ Literacy of mother } & Literate & 118 & 96.72 \\
\hline & Illeterate & 4 & 3.28 \\
\hline \multirow{3}{*}{$\begin{array}{l}\text { Annual } \\
\text { household income } \\
\text { (approximated) }\end{array}$} & Less than $\$ 2000$ & 15 & 12.29 \\
\hline & $\$ 2000$ to $\$ 5000$ & 56 & 45.90 \\
\hline & More than 5000 & 51 & 41.81 \\
\hline \multirow{3}{*}{ Feeding trends } & Usually takes normal meals & 50 & 40.98 \\
\hline & Difficulty in taking normal meals & 40 & 32.79 \\
\hline & Overeating tendency & 32 & 26.23 \\
\hline \multirow{2}{*}{ Liking to junk foods } & Very much & 66 & 54.10 \\
\hline & Not so much & 56 & 45.90 \\
\hline \multirow{2}{*}{$\begin{array}{l}\text { Screen habit while } \\
\text { eating }\end{array}$} & Watches TV/tablets/mobiles & 57 & 46.72 \\
\hline & Does not watch anything & 65 & 53.28 \\
\hline \multirow{2}{*}{ Sleeping habit } & Has normal sleep & 79 & 64.76 \\
\hline & Wakes up many times at night & 43 & 35.24 \\
\hline \multirow{2}{*}{$\begin{array}{l}\text { Involvement in } \\
\text { physical activities }\end{array}$} & Usually likes playing outdoors & 49 & 40.16 \\
\hline & $\begin{array}{l}\text { Stays inside house watching TV or playing games in } \\
\text { mobile phones }\end{array}$ & 73 & 59.84 \\
\hline
\end{tabular}

impact on health of child in future. People are still unaware of the situation and may lead to epidemic causing increase risk of diabetes, hypertension and other diseases in future.

In the present study the average age of the child was $2.9 \pm 0.4$ years. The youngest child was 24 months whereas the oldest among study population was 48 months. In similar type study done by Fatemeh et al. the mean age was $3.5 \pm 0.5$ years. [11] Systematic reviews have discovered in increasing prevalence of obesity and overweight among children. The Global Burden of Disease Study estimated that the prevalence of obesity/overweight in children in developing countries was $12.9 \%$ for boys and $13.4 \%$ for girls in 2013 which is similar to our study. [12] According to a research done by Fatemeh et al. in Birjand, Iran the prevalence of overweight was $10.1 \%$ ( $11.7 \%$ in females and $9.6 \%$ in males) which is just opposite among males and females when compared my study.[11] Similar to our study the study done in United States found that prevalence of obesity in children and adolescents aged 2 to 19 years in 2011-2014 was $17.0 \%$, while the prevalence of extreme obesity was 5.8\%.[13] The WHO reported that childhood overweight and obesity could be the results of the changing life style including consuming high energy-dense diets that are high in fat content and carbohydrate but low in vitamins and minerals, and doing less physical activity because of the sedentary lifestyles.[14] The study clearly showed that the overweight was significantly associated with sedentary lifestyles of children and higher socio-economic status of the family (Table 2). In this study the prevalence 
of overweight including obesity was more in male children than in female children which shows the trends of feeding more in male child than female child in Nepalese society.

Limitations: The trend of studies in developing countries is only focused in urban middle class and upper middle class families and furthermore the sample size was also very small. The problem of overweight and obesity in children is increasing and further broad research with larger sample size is recommended.

\section{CONCLUSION}

The prevalence of overweight found in this study is not big as in developed countries but it is increasing rapidly in Nepal due to sedentary lifestyles and improper dietary habits among children especially in the cities. Thus, proper attention should be given for the intervention on causes of overweight among pre-school children in order to avoid the diseases like hypertension, diabetes, etc in future.

\section{ACKNOWLEDGEMENTS}

We gratefully acknowledge the University Grants Commission, Sanothimi, Bhaktapur, Nepal for providing the support to conduct this study.

\section{CONFLICT OF INTEREST}

None

\section{REFERENCES}

1. Misra A, Khurana L. Obesity and the metabolic syndrome in developing countries. J Clin Endocrinol Metab 2008; 93: S9-S30.

2. Rivera JA, de Cossio TG, Pedraza LS, Aburto TC, Sanchez TG, Martorell R. Childhood and adolescent overweight and obesity in Latin America: a systematic review. Lancet Diabetes Endocrinol 2014; 2: 321-32.

3. Plachta-Danielzik S, Kehden B, Landsberg B, et al. Attributable risks for childhood overweight: evidence for limited effectiveness of prevention. Pediatrics. 2012; 130: e865.
4. de Onis M, Blossner M, Borghi E. Global prevalence and trends of overweight and obesity among preschool children. Am J Clin Nutr 2010; 92:1257-64. [PMID: 20861173]

5. Olaya B, Moneta MV, Pez O, et al. Country-level and individual correlates of overweight and obesity among primary school children: a cross-sectional study in seven European countries. BMC Public Health 2015; 15: 1-12.

6. Harris KM, Gordon-Larsen P, Chantala K, Udry $R$. Longitudinal trends in race/ethnic disparities in leading health indicators from adolescence to young adulthood. Arch Pediatr Adolesc Med 2006; 160(1): 74-81.

7. Schwimmer JB, Burwinkle TM, Varni JW. Health-related quality of life of severely obese children and adolescents. JAMA 2003; 289: 1813-1819.

8. Epstein LH, Paluch RA, Beecher MD, Roemmich JN. Increasing healthy eating vs. reducing high energy-dense foods to treat pediatric obesity. Obesity (Silver Spring) 2008; 16(2): 318-326.

9. Johnson LD, Delva J, O'Malley PM. Sports participation and physical education in American secondary schools: current levels and racial/ethnic and socioeconomic disparities. Am J Prev Med 2007; 33: S195-S208.

10. World Health Organization. WHO child growth standards: length/height-for-age, weight-for-age, weightfor-height and body mass index-for-age: Methods and development. Geneva, Switzerland: World Health Organization; 2006. Available at http://www.who.int/ childgrowth/publications/technical_report_pub/en/index. html

11. Fatemeh T, Mohammad HT, Toba K,Afsaneh N, Sharifzadeh $G$. Prevalence of overweight and obesity in preschool children (2-5 year-olds) in Birjand, Iran. BMC Research Notes 2012: 5: 529-31

12. $\mathrm{Ng} \mathrm{M}$, Fleming T, Robinson $\mathrm{M}$, et al. Global, regional, and national prevalence of overweight and obesity in children and adults during 1980-2013: a systematic analysis for the Global Burden of Disease Study 2013. Lancet 2014; 384: 766-81.

13. Ogden CL, Carroll MD, Lawman HG, et al. Trends in obesity prevalence among children and adolescents in the United States, 1988-1994 through 2013-2014. JAMA 2016; 315: 2292-9.

14. World Health Organization Consultation on Obesity. Preventing and managing the global epidemic: report of a WHO consultation on obesity, Geneva, Switzerland, June 3-5, 1997. Geneva, Switzerland: World Health Organization; 1998. 